\section{EL RIESGO EN LA ACTUALIZACIÓN POST-DESASTRE DE INSTRUMENTOS DE PLANIFICACIÓN TERRITORIAL COMUNALES EN CHILE 2010-2014}

Roberto Moris $^{1,3, *}$, Pablo Contrucci ${ }^{2}$ y Andrea Ortega ${ }^{3}$

\section{RESUMEN}

Este artículo revisa el desarrollo de estudios de evaluación de riesgos y su incorporación en Instrumentos de Planificación Territorial (IPT) en zonas afectadas por el terremoto y tsunami del 27 de febrero de 2010 (27F) durante los cinco años posteriores al evento. Se analizaron los procesos de modificación de los Planes Reguladores Comunales (PRC) de las comunas de las regiones de O'Higgins, Maule y Bío-Bío. En gran parte de las comunas afectadas se generaron estudios fundados de riesgo como insumos para la actualización de sus planes reguladores. El proceso evidenció que existían comunas y localidades que ni siquiera tenían límite urbano, y casos de PRC sin actualizaciones, por lo que se encontraban vulnerables ante nuevos eventos. Esto sumado al hecho de que los PRC solo abarcan las áreas urbanas y que sectores rurales que fueron afectados, en su mayoría no contaban con instrumentos de planificación. El análisis deja de manifiesto la urgencia de avanzar en el perfeccionamiento de los instrumentos de planificación territorial en cuanto a la actualización de estudios de riesgo en procesos post-desastre.

\section{PALABRAS CLAVE}

Estudios de riesgos, planificación urbana, Instrumentos de planificación territorial, planes reguladores comunales, Chile

\section{ABSTRACT}

This article reviews the development of risk assessment studies and their incorporation into Territorial Planning Instruments (IPT) in areas affected by the earthquake and tsunami of the 27th February 2010 (27F) during the following five years after the event. The processes of modification of the Communal Regulatory Plans (PRC) of the communes of the O'Higgins, Maule and BíoBío regions were analyzed. In many of the affected communes, well-founded risk studies were generated as inputs for their regulatory plans. The process revealed that there were communes and towns that did not even have an urban boundary, and cases of PRC that had not been updated, which made them vulnerable to new events. This, coupled with the fact that PRCs only cover urban areas and that most of the rural sectors that were affected did not have planning instruments and risk zoning. Despite the large number of studies for amending regulatory plans and areas at risk, very few plans were successfully approved. The analysis shows that there is an urgent need to advance in the improvement of territorial planning instruments in terms of the updating of the risk studies in post-disaster processes.

\section{KEYWORDS}

Risk studies, urban planning, territorial planning instruments, community regulatory plans, Chile

\author{
1. Instituto de Estudios \\ Urbanos y Territoriales, \\ Pontificia Universidad \\ Católica de Chile, Santiago, \\ Chile \\ 2. División de Desarrollo \\ Urbano. Ministerio de \\ Vivienda y Urbanismo, \\ Santiago, Chile.
}

3. Centro de Investigación para la Gestión Integrada de Riesgos de Desastres Naturales Desastres (CIGIDEN), Santiago, Chile.

*Autor de correspondencia: rmoris@uc.cl

\section{RECIBIDO}

31 de enero de 2017

\section{ACEPTADO}

20 de febrero de 2017

\section{PUBLICADO}

15 de julio de 2017

\section{Formato cita}

Recomendada (APA)

Moris, R., Contrucci, P. \& Ortega, A. (2017).

El riesgo en la actualización post-desastre de instrumentos de planificación territorial comunales en Chile 2010 - 2014. REDER, 1(1), pp.85-100.

\section{(ब) $\triangle$}

Todos los artículos publicados en REDER siguen una política de Acceso Abierto y se respaldan en una Licencia CreativeCommons Atribución-NoComercial 4.0 Internacional.

Revista de Estudios

Latinoamericanos sobre Reducción del Riesgo de Desastres (REDER)

Diseño: Lupe Bezzina Tipografías: Hospital 


\section{INTRODUCCIÓN}

El terremoto de magnitud $8.8 \mathrm{Mw}$ y el posterior tsunami que golpeó la zona centro sur de Chile la madrugada del 27 de febrero de 2010 (27F) tuvo una extensión de 800 kilómetros (MINVU, 2013) y afectó al $69 \%$ de las comunas chilenas, en las cuales habita el $75 \%$ de la población nacional'. Esta catástrofe y sus consecuencias revelaron las carencias de los territorios y también la de los instrumentos con que cuenta el país, específicamente en cuando a planes reguladores, mapas de riesgos, registros, cartografías y déficit de urbanización (Gobierno de Chile, 2014).

El proceso de reconstrucción implementado en los primeros 5 años dio cuenta de la falta de un marco institucional para esta fase de recuperación en el ciclo de la gestión del riesgo. La persistencia de actuar sectorialmente desde un enfoque de déficit y cobertura, sin definir un liderazgo interinstitucional, con estándares y estrategias de planificación territorial integrada, generaron condiciones que no permitieron sentar la bases de una reconstrucción sustentable y equitativa (Moris, 2014; Gobierno de Chile, 2014).

\section{Mitigación de riesgos, resiliencia y el rol de la planificación}

El potencial efecto devastador que los eventos naturales extremos tienen en las sociedades se ha vuelto un tema particularmente relevante en las regiones en desarrollo, donde los países están experimentando un rápido crecimiento de población con intensa urbanización y posiblemente aumentando su exposición y vulnerabilidad (OECD, 2012). A causa de la creciente conciencia sobre la debilidad frente a diversas amenazas, se ha configurado un nuevo contexto internacional para la promoción del conocimiento y la evaluación de riesgos. Por ejemplo, la "Estrategia Internacional para la Reducción de Desastres" de la ONU (ISDR) fue establecida en 1999, y, en 2004 junto con la "Indian Ocean Earthquake and Tsunami", lideraron el desarrollo del Marco Acción de de Hyogo en 2005. Otras iniciativas internacionales como el Programa de las Naciones Unidas de Identificación Global de Riesgos (GRIP) y el Fondo para la Reducción y Recuperación de Desastres del Banco Mundial (GFDRR) también se crearon en respuesta al Marco de Hyogo y los compromisos en Sendai (2015). En iniciativas paralelas, regionales, como los promovidos por la Comisión Europea sobre Riesgos para la Evaluación y Cartografía en Gestión de Desastres, ponen de relieve la necesidad de una gestión integrada de riesgos.

En este contexto se ha destacado la necesidad de abordar los factores subyacentes del riesgo para una disminución del riesgo y de las pérdidas. Diversas instituciones han desarrollado metodologías de evaluación y proyección de daños, visto el alto impacto que los desastres ocasionan en las economías regionales y locales. Por ejemplo, los desastres estudiados por la CEPAL (2014) entre 1972 y 2011 fueron responsables de 309.742 fallecimientos, afectaron a alrededor de 30 millones de personas y provocaron un impacto económico total de aproximadamente 213.000 millones de dólares, de los cuales, 150.000 millones de dólares corresponden a daños y 63.000 millones de dólares corresponden a pérdidas (Bello, Ortiz \& Samaniego, 2012).

Las pérdidas ocasionadas a partir de los desastres han ido en aumento, provocando graves consecuencias para la supervivencia, la dignidad y los medios de vida de los seres humanos, especialmente para los sectores más vulnerables (UNISDR, 2005). El riesgo de desastres es un motivo de creciente preocupación mundial cuyo impacto en una región puede repercutir en la vulnerabilidad de otra, potenciando las condiciones de subdesarrollo, desigualdades socioeconómicas, urbanización en zonas de alto riesgo y degradación del medio ambiente.

Tanto el Marco de Acción de Hyogo de 2005 como el Marco de Sendai en 2015 recomiendan el fortalecimiento de la planificación territorial para enfrentar los factores subyacentes del riesgo. Priorizando la elaboración de planes para la reducción de los riesgos de desastre que consideren la diversidad cultural, los diferentes grupos etarios y los grupos vulnerables. También se indica que se debe "dotar tanto a las comunidades como a las autoridades locales de los medios para controlar y reducir los riesgos de desastre, asegurándoles el acceso a la información, los recursos y la autoridad necesarios para emprender actividades de reducción de los riesgos de desastre" (UNISDR, 2005).

Asimismo, la "Organización para la Cooperación y el Desarrollo Económicos" (OECD) elaboró un acuerdo internacional que indica la necesidad de avanzar hacia evaluaciones integrales. Esto implica un cambio de enfoque general en la modelación de riesgos más allá del cálculo de los impactos de amenaza, que incorpora información sobre la vulnerabilidad y la exposición. La cuantificación de la exposición al riesgo comprendiendo diversos elementos que interactúan en las ciudades y asentamientos humanos es un reto al que se suma además la necesidad de considerar la vulnerabilidad social o la capacidad de resiliencia (OECD, 2012)
1. Gobierno de Chile (2014).

"Diagnóstico estado de la reconstrucción terremoto y tsunami 27 de febrero de 2010". Delegación Presidencial para la Reconstrucción. Gobierno de Chile. Santiago, 4 de Julio 2014. 
Según la "Environmental Protection Agency" (EPA) de EEUU, las evaluaciones a desarrollar en el marco de una planificación ambiental integral debieran plantearse desde una visión ecosistémica del entorno geográfico, en vínculo con asociaciones entre las partes interesadas (EPA, 2000). Por otro lado, la mitigación, piedra angular de la gestión de emergencias, involucra una toma de acciones sostenidas para reducir o eliminar los riesgos a largo plazo, que afectan tanto a las personas como a bienes públicos y privados. Este tipo de estrategias de mitigación construyen resiliencia en las comunidades y promueven su sostenibilidad (Schwab, 2010).

En este sentido, la resiliencia de la sociedad civil estaría determinada por leyes, políticas e instituciones (Swanstrom, 2008) y esta capacidad debiera orientarse hacia una meta, en la cual la inclusión de la dimensión normativa es crucial (Bahadur and Tanner, 2014). Para definir una base normativa que responda de manera exitosa y equitativa, es necesario reflexionar qué es lo que se está haciendo ante las dinámicas específicas, cuáles son los criterios de decisión y si la capacidad de recuperación es, en consecuencia, un problema o no (Smith \& Stirling, 2010).

Ante la necesidad de establecer un nexo entre la dimensión normativa y el desarrollo de los procesos, el rol mediador de los planificadores entre las comunidades y las autoridades involucradas tras la institucionalidad se vuelve fundamental. Asimismo, los planificadores deben aprender acerca de la interacción entre los sistemas naturales y el entorno construido para tomar decisiones informadas sobre los posibles resultados de sus decisiones (Schwab, 2010). En el año 2007, la American Planning Association, en su afán por indicar principios claves para la práctica de la planificación definió los siguientes lineamientos de acción:

- Actuar antes de un desastre: los daños podrían evitarse mediante una buena planificación.

- La mitigación requiere paciencia, seguimiento y evaluación continua.

- Ser estratégico y buscar oportunidades de aprendizaje.

- Las comunidades necesitan líderes que aboguen por una causa.

- La implementación de acciones depende de las voluntades políticas.

- Los planificadores deben tener en cuenta los intereses de las partes.

- Enfatizar en la planificación de objetivos múltiples.

- Evaluar las oportunidades desde un plan integral para relocalización en densidad.

- Emular la tendencia de construcción verde.

- Comunicar los riesgos.

En el caso de Estados Unidos, según el acuerdo "Disaster Mitigation Act" (DMA 2000), se establece la intención de que los gobiernos locales desde sus planes, denominados "Local Hazard Mitigation Plans" (LHMPs), se integren a los planes federales (Schwab, 2010). Desde esta visión regional-local, la legislación debería indicar cómo las recomendaciones de mitigación serían incorporadas a los planes integrales. Las comunidades que no cuentan con un plan integral u otros mecanismos de planificación similar, deben declarar cómo las recomendaciones de mitigación se aplicarían. Además, las acciones de mitigación desde otros medios u herramientas de aplicación deben ser descritos (FEMA, 2009).

Entonces, la principal herramienta para una efectiva mitigación de riesgos surgiría desde un proceso de planificación ambiental integral (Schwab, 2010). Sin embargo, a pesar de esta premisa, en Chile no contamos con estrategias de mitigación de riesgos que estén articuladas adecuadamente con los Instrumentos de Planificación Territorial (IPT), donde a menudo los mapas de amenazas y vulnerabilidad son inconsistentes, no están disponibles o son inaccesibles (OECD, 2012). Por lo tanto, los periodos de recuperación post-desastre representan una oportunidad para actualizar los instrumentos y permitir que los territorios estén mejor preparados.

\section{MARCO LEGAL EN CHILE: INSTRUMENTOS DE PLANIFICACIÓN TERRITORIAL Y LEY DE SISMOS Y CATÁSTROFES}

\section{Instrumentos de Planificación Territorial en Chile}

Si bien Chile cuenta con una Política Nacional de Gestión de Riesgo de Desastres desde 2014 que está en frecuencia con Hyogo y Sendai, aún están pendientes reformas que aborden el ordenamiento y planificación territorial. En la actualidad existe una diversidad de Instrumentos de Planificación Territorial (IPT) que operan esencialmente en el ámbito urbano, mientras que el ordenamiento integral del territorio es un desafío pendiente, existiendo una gran asimetría entre el territorio urbano y el rural (Ferrada-Nehme \& IEUT, 2011). 
En Chile la directriz del sistema de ordenamiento territorial se encuentra establecida desde el inciso $2^{\circ}$ del artículo 3 de la Constitución Política de la República, que señala: "Los órganos del Estado promoverán el fortalecimiento de la regionalización del país y el desarrollo equitativo y solidario entre las regiones, provincias y comunas del territorio nacional". Sin embargo, tales declaraciones no se concretan a nivel de IPT, pues el ordenamiento jurídico carece de una política nacional de ordenamiento territorial que fije los criterios que permitan alcanzar los objetivos plasmados a nivel constitucional.

A nivel regional tampoco existe un instrumento preciso que fije directrices en cuanto a ordenamiento del territorio, sin perjuicio de la Estrategia Regional de Desarrollo. Éste es un instrumento de planificación que busca incidir en el uso del suelo desde distintos ámbitos que la región pretende seguir para su desarrollo. En este contexto, son múltiples los sectores que cuentan con competencias para regular y/o planificar los distintos usos que pueden converger en el territorio regional, sin que necesariamente haya coordinación o una mirada transversal entre éstos. La próxima formalización de los Planes Regionales de Ordenamiento Territorial (PROT) vendrá a generar nuevas condiciones en la escala regional y una mayor consideración de los riesgos. Pero es en los instrumentos de planificación territorial a escala comunal e intercomunal donde se podrían establecer avances concretos en el corto plazo.

En esta diversidad de instrumentos es posible identificar aquellos que implican procesos planificadores, es decir, procesos racionales de tomas de decisiones, basados en un diagnóstico de la realidad con miras a generar efectos futuros y que, conforme a dicho proceso, expresan la distribución espacial de los usos de suelo en conformidad con los objetivos de desarrollo económico y social. Respecto de los instrumentos estrictos, la clasificación da cuenta de la obligatoriedad o no del instrumento, entre los cuales se clasifican como normativos o indicativos.

En este contexto, es posible realizar una multiplicidad de distinciones, entre las cuales destaca la asimetría existente entre la planificación urbana y la rural. La planificación urbana conforma un sistema jerarquizado, tanto a nivel normativo como territorial, que distingue las diversas escalas de aplicación. Esta regulación se encuentra en la Ley General de Urbanismo y Construcciones (LGUC) y en la Ordenanza de Urbanismo y Construcciones (OGUC).

En el artículo 2.1.1 de la OGUC se indica lo siguiente: "El proceso de planificación urbana orientará o regulará, según el caso, el desarrollo de los centros urbanos a través de los IPT que se señalan en este capítulo. Cada uno de dichos instrumentos tendrá un ámbito de acción propio, tanto en relación a la superficie del territorio que abarcan, como a las materias y disposiciones que contienen" (OGUC, 1992). En el artículo 2.1.2 se especifican los distintos IPT según su ámbito:

- Plan Regional de Desarrollo Urbano

- Plan Regulador Intercomunal o Metropolitano (PRI/PRM)

- Plan Regulador Comunal (PRC) con sus planos seccionales que lo detallen

- Plan Seccional

- Límite Urbano

De los instrumentos indicados, los PRI/PRM, PRC, Plan Seccional y Límite Urbano corresponden a instrumentos normativos, mientras el Plan Regional de Desarrollo Urbanos es indicativo. Si bien todos estos instrumentos podrían considerar variables de riesgo, en términos normativos, los instrumentos más relevantes son los PRC y los PRI/PRM, dado que son capaces de zonificar y generar las restricciones u obras de mitigación necesarias en las zonas de riegos. Sobre los PRI/PRM, una importante diferencia está dada por el hecho de que no regulan sólo el área urba$\mathrm{na}^{2}$, sino que incorporan además el área rural de las comunas que están incluidas en los sectores intercomunales ${ }^{3}$

Otro instrumento indicativo a considerar, en relación a variables de riegos, es la Zonificación de Uso de Borde Costero (ZUBC), la cual tiene como objetivo realizar un ordenamiento de los usos del territorio costero compatibilizando distintos intereses sobre el mismo y planificando sus usos mediante un proceso de participación ciudadana. El marco legal se encuentra en el D.S. N 475 de 14 de diciembre de 1994, Ministerio de Defensa Nacional, Subsecretaría de Marina, establece la Política Nacional de Uso del Borde Costero del Litoral de la República y crea la Comisión Nacional de Uso del Borde Costero del Litoral (CNUBC).

Finalmente, es necesario precisar que al momento de actualizar los IPT después del $27 \mathrm{~F}$ las condiciones para la zonificación de riesgos estaban normadas por el art. 2.1.17 de la LGUC y por la Circular DDU 227 (MINVU 2009), la cual instruye respecto de la formulación, ámbitos de acción de
2. El artículo 1.1.2. de la OGUC define área urbana como: "la superficie de territorio ubicada al interior del limite urbano, destinada al desarrollo armónico de los centros poblados y sus actividades existentes y proyectadas por el instrumento de planificación territorial". Define área rural como: "territorio ubicado fuera del límite urbano".

3. El contenido de los PRI/PRM se encuentra en el artículo 2.1.7 de la OGUC, complementado mediante Circular DDU Nº 219, ORD. № 0353 de 29 de mayo de 2009 , de la División de Desarrollo Urbano del MINVU. 
los PRC y los procesos de aprobación y modificación.

Como se puede observar en el siguiente cuadro, en el periodo de post-desastre el MINVU generó las circulares DDU 244, 245, 248, 269 y 276 que vinieron a dar orientaciones puntuales respecto a procedimientos de construcción y actualización de los IPT.

$\begin{array}{ll}\text { Circular DDU } & \text { Contenidos } \\ 244 & \begin{array}{l}\text { Distribuye formularios únicos nacionales (FUN) para tramitar autorizaciones de } \\ \text { construcciones en zonas afectadas por catástrofe, ante las Direcciones de Obras Municipales } \\ \\ \text { Complementan procedimientos simplificados para aprobación de nuevas construcciones } \\ \text { y regularización de edificaciones existentes ubicadas en zonas declaradas "afectadas por } \\ \text { catástrofe" }\end{array} \\ & \begin{array}{l}\text { Aclara procedimientos simplificados para aprobación de nuevas construcciones } \\ \text { y regularización de edificaciones existentes ubicadas en zonas declaradas "afectadas por } \\ \text { catástrofe" }\end{array} \\ & \text { Refiere a necesidad de incluir la definición de áreas de riesgo por amenaza de incendio en IPT }\end{array}$

Tabla 1. Circulares DDU MINVU del periodo 2010 - 2014.

Fuente: Rinaldi (2016) en base a MINVU.

En 2012 se ejecutó una modificación a la LGUC denominada Ley de Reconstrucción (Ley 20.582 de 13/04/2012). A pesar de su denominación esta modificación no entregó un marco de institucionalidad a la fase de reconstrucción en términos integrales. En el año 2014 el Gobierno entrante de Bachelet desarrolló un diagnóstico de la reconstrucción del 27F que concluyó con la necesidad de avanzar en el marco institucional de la reconstrucción. Sin embargo, no se avanzó sustantivamente en esta línea con posterioridad.

El proyecto de ley en discusión para crear el Servicio Nacional de Gestión de Riesgos y Emergencia que sustituiría a la ONEMI avanza hacia la gestión del ciclo del riesgo más allá de la emergencia. El proyecto propone una estructura de coordinación multisectorial y crea nuevos instrumentos de planificación y preparación. Sin embargo, en lo que respecta a la reconstrucción no se define un marco específico, ni acciones que tiendan a su formalización. Si bien se alude a los mapas de riesgo, no se indica cómo se relacionarían con el marco normativo de los instrumentos de planificación territorial.

Por otro lado, el avance que podría tener un mayor impacto es la modificación del artículo 2.1.17 que está en proceso de tramitación desde 2015. Este proyecto, también denominado de Reconstrucción, fortalece las capacidades de los IPT respecto a la zonificación de riesgos y la aplicación de normas urbanísticas. Los principales ajustes son los siguientes:

- Se mejora la definición de Riesgo y Amenaza, pero se mantiene la denominación de riesgo a lo que internacionalmente se tiene como amenaza. Por lo tanto, se seguirá denominando "mapas de riesgo" a los "mapas de amenazas" que son incorporados en los IPT.

- Se amplía la definición y cantidad de tipos de riesgos posibles de incorporar en los IPT.

- Se avanza en la definición de áreas de riesgo y zonas de riesgo.

- Se incorpora el concepto de susceptibilidad y la consecuente asignación de grados.

- Se avanza en la definición de estudio fundado de riesgo, pero no en su ejecución, sin avanzar en perfeccionamientos respecto de metodologías y procedimientos.

\section{Ley de Sismos y Catástrofes}

Dado que fue necesario generar modificaciones excepcionales a los planes reguladores en ciertas comunas afectadas post 27F, estas modificaciones se realizaron aplicando la Ley $N^{0} 16.282$ sobre sismos y catástrofes ${ }^{4}$. El "Artículo $27^{\circ}$. Aplicación de la Ley $n^{0} 16.282$ para la modificación de los planes reguladores en comunas afectadas por un sismo o catástrofe", indica que el Ministerio de la Vivienda y Urbanismo (MINVU) debe, dentro del plazo de noventa días siguientes a la recepción del acuerdo respectivo, pronunciarse acerca de las modificaciones que aprueben las Municipalidades afectadas por un sismo o catástrofe a sus respectivos planos reguladores.

Asimismo, se indica que la modificación de los PRC que acuerde la Municipalidad debe contar con la aprobación del especialista antisísmico que la asesore o que fuere designado para este efecto por el Colegio de Ingenieros de Chile para prestarle atención gratuita.

Cuando las comunas carezcan de planos reguladores definitivos, el presidente de la República puede, dentro de los dos años siguientes al sismo o catástrofe, aprobar proyectos parciales o anteproyectos de planos reguladores elaborados por la Municipalidad respectiva o por la División de

4. Ministerio de Hacienda (1971) Ley $\mathrm{N}^{\circ} 16.25$. DFL 1 , Interior № 1 D.O. 15.05.1971. http://www.leychile.cl/ Navegar?idNorma $=214428$. 
Desarrollo Urbano (DDU) del MINVU. Además, las Municipalidades de las zonas afectadas por el sismo o catástrofe podrán permutar los terrenos e inmuebles que sean necesarios para ejecutar el plan de remodelación" 5

Esta ley además dispone que el MINVU debe, dentro del plazo de 90 días siguientes a la recepción del acuerdo respectivo, pronunciarse acerca de las modificaciones que aprueben las Municipalidades afectadas, debiendo dictarse de inmediato el decreto supremo correspondiente si éstas fueren aprobadas. Este procedimiento exige de forma obligatoria la entrega de una memoria explicativa con los antecedentes técnicos base, la ordenanza local con las disposiciones normativas y planos que expresan gráficamente la ordenanza. Asimismo, se debe incluir un informe de la propuesta del plan regulador de un especialista antisísmico, elaborados por un geólogo o un ingeniero con especialidad en sismología.

Sin embargo, es optativo anexar el "estudio fundado de riesgos" ${ }^{6}$ a la memoria explicativa. Este anexo debiera incluir zonas inundables o potencialmente inundables; zonas propensas a avalanchas, rodados, aluviones o erosiones acentuadas; zonas con peligro de ser afectadas por actividad volcánica, ríos de lava o fallas geológicas; zonas o terrenos con riesgos generados por la actividad o intervención humana.

\section{MODIFICACIÓN DE PRC Y FORMULACIÓN DE ESTUDIOS DE RIESGOS A TRAVÉS DE LA LEY DE SISMOS Y CATÁSTROFES POST 27F}

El gran terremoto y posterior tsunami del 27F, que tuvo su epicentro en el Mar Chileno, frente a las localidades de Curanipe y Cobquecura ${ }^{7}$, ubicadas en la Región del Maule, afectó a cinco regiones $^{8}$, es decir, 234 comunas en las cuales habitaba una población de más de 12 millones de habitantes ${ }^{9}$. Según el MINVU (2010), 66 comunas requirieron estudios de riesgo y modificación o actualización de sus PRC ${ }^{10}$. Las tres regiones más afectadas por la catástrofe fueron la VI Región de O'Higgins, VII Región del Maule (epicentro) y VIII Región del Bio-Bío, en las cuales 42 comunas requirieron estudios de riesgo y modificación o actualización de sus $\mathrm{PRC}^{11}$ (Figura 1)

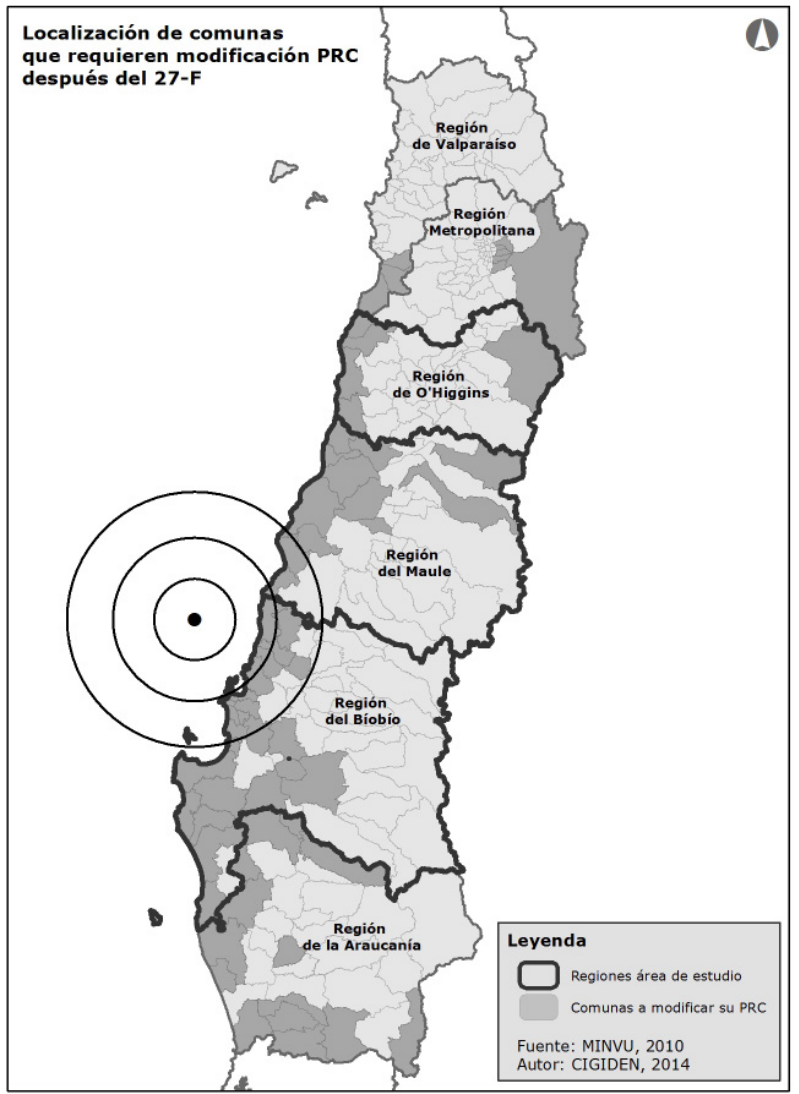

Figura 1. Mapa que muestra las comunas que requirieron estudios de riesgo y modificación o actualización de sus PRC. Fuente: CIGIDEN (2014) en base a información MINVU (2010).
5INVU (2010). Procedimiento para Actualizar Planes Reguladores. Disponible en línea: www.minvu.cl/.../ download.aspx?...Procedimiento\%20 Actualización\%2o...

6. OGUC, DS 75 del año 2001. Áreas de Riesgo Artículo 2.1.17

7. Sistema Sismológico Nacional de la Universidad de Chile (27 de febrero de 2010). "Informe de sismo". Disponible en: http://ssn.dgf.uchile.cl/events/ sensibles/2010/02/20100227063428 html

8. V de Valparaíso, VI Región de O’Higgins, VII Región del Maule, VIII Región del Biobío y Región Metropolitana de Santiago.

9. Se utiliza base de datos Censo 2002 INE (2002). Datos Demográficos Censo 2002 [en línea]. Disponible en: www.ine.cl/canales/usuarios/censos_digitalizados.php

1.. MINVU (2010). Procedimiento para Actualizar Planes Reguladores. www.minvu.cl/.../download.aspx?... Procedimiento\%2oActualización\%2o.

11. En VI Región de O'Higgins requerían estudios las comunas de Navidad, Litueche, Pichilemu, Paredones y Machalí. En VII Región del Maule requerían estudios las comunas de Vichuquén, Licantén, Curepto, Hualañé, Constitución, Pencahue, Maule, Empedrado, Chanco, Pelluhue, Romeral y Molina. En VIII Región del Biobío requerían estudios las comuna de Cobquecura, Quirihue, Treguaco, Portezuelo, Coelemu, Tomé, Penco, Talcahuano, Hualpén, Concepción, San Pedro de La Paz, Chiguayante, Coronel, Hualqui, Yumbel, Lota, Laja, Los Angeles, Nacimiento, Arauco, Curanilahue, Lebu, Los Alamos, Cañete y Tirúa. 
El Estado de Chile después de la catástrofe implementó un programa para el desarrollo de estudios integrados de riesgo en las localidades costeras de cuatro regiones afectadas por el terremoto y tsunami. Por primera vez en Chile, equipos multidisciplinarios desarrollaron modelaciones y evaluaciones de amenazas y riesgos de tsunami, inundación fluvial, remoción en masa, licuefacción y amplitud sísmica (MINVU, 2013). Para las comunas afectadas se generaron los "estudios fundados de riesgo"12 necesarios para la actualización de sus PRC. Fueron 52 estudios para 61 PRC que indican la necesidad de ajustar el instrumento comunal. De los estudios, 26 corresponden a comunas del borde costero y 26 a comunas de la zona interior entre las regiones de Valparaíso y la Araucanía que presentaron riesgos puntuales y acotados ${ }^{13}$.

Esta iniciativa permitió contar con estudios de riegos para las comunas de las regiones más afectadas por la catástrofe por encargo de la Subsecretaría de Desarrollo Regional en un plazo de 9 meses, incluyendo mapas de amenazas, de vulnerabilidad y riesgo. Los estudios establecieron zonas de riesgo y exposición de infraestructura crítica y de la población. Una parte importante de los estudios se transformó en insumos para la actualización de los IPT, con disímil éxito en su tramitación. Asimismo, con los resultados de los estudios de riesgo, desde el MINVU se desarrollaron 25 Planes Maestros para el borde costero de las localidades afectadas, los cuales priorizaron "las obras necesarias para garantizar un regreso seguro a la costa" (MINVU, 2011).

Para el caso de las regiones de Maule y O'Higgins, se desarrolló un "Estudio de riesgo de sismos y maremoto para comunas costeras de las Regiones de O'Higgins y del Maule" (Moris et al, 2010) desde el Observatorio de Ciudades y el Instituto de Estudios Urbanos y Territoriales de la Pontificia Universidad Católica de Chile. Por otro lado, para la región del Bio-Bío se desarrolló un "Estudio de riesgo de sismos y maremoto para comunas costeras de la región del Bío-Bío" por parte del Laboratorio de Estudios Urbanos de la Universidad del Bío-Bío (LEU, 2010).

Los estudios de riesgos en el marco de la definición de los IPT abarcan generalmente amenazas naturales como inundación y anegamiento por desborde de cauces o por acumulación de aguas lluvias, y amenaza de remoción en masa, asociado a fuertes pendientes de laderas de cerros o taludes de esteros y ríos. En este contexto, se observa que un bajo porcentaje de los PRC vigentes en 2010 de las comunas Maule y O'Higgins incluía también amenazas por marejadas o tsunamis, o amenazas de sismos, y los que sí lo hacían, por lo general no delimitaban un área de amenaza asociada a estos eventos (Moris et al, 2010).

Posteriormente al 27F la mayor parte de los IPT en formulación o actualización de las regiones afectadas fueron revisadas a la luz de esta catástrofe. Algunos PRC fueron modificados, otros se encuentran a la espera de las recomendaciones de éste y otros estudios de riesgo, para incluirlas dentro de los proyectos en desarrollo (Moris et al, 2010).

\section{Caso de la Región de O’Higgins}

La región de O'Higgins cuenta con 33 comunas $^{14}$ de las cuales 5 requirieron modificación o actualización de su PRC (MINVU, 2010) (Figura 2).

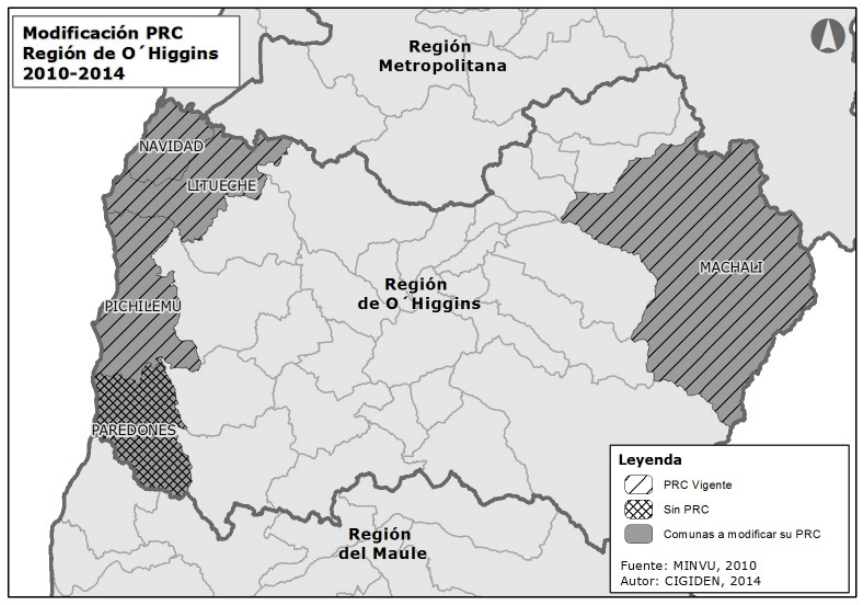

Figura 2. Mapa que muestra la cantidad de comunas que requirieron estudios de riesgo en la Región de O'Higgins y cuáles de estos tienen PRC vigente y no lo tienen a la fecha. Fuente: CIGIDEN (2014) en base a información MINVU $(2010,2014)$.

\author{
12. OGUC, DS 75 del año 2001. Áreas \\ de Riesgo Artículo 2.1.17. \\ 13. Información según datos MINVU \\ (2013). "Reconstrucción urbana \\ post 27 F. Instrumentos de Gestión y \\ Planificación Territorial". Dirección \\ de Reconstrucción, Ministerio de \\ Vivienda y Urbanismo [en línea]. \\ Disponible en: $h t t p: / / w w w . m i n v u . c l /$ \\ opensite_20131008122013.aspx \\ 14. Mostazal, Graneros, Codegua, \\ Rancagua, Machalí, Las Cabras, \\ Coltauco, Doñihue, Olivar, Coinco, \\ Requínoa, Peumo, Quinta de Tilcoco, \\ Pichidegua, San Vicente, Malloa, \\ Rengo, Navidad, Litueche, La Estrella, \\ Pichilemu, Marchihue, Paredones, \\ Peralillo, Palmilla, San Fernando, \\ Pumanque, Santa Cruz, Nancagua, \\ Placilla, Lolol, Chépica y Chimbarongo
}


De estas comunas, sólo Paredones no poseía PRC, el cual fue desarrollado en 2014 incluyendo los antecedentes generados por el estudio OCUC 2010 (Moris et al, 2010).

Por otro lado, la comuna de Navidad y Litueche poseían PRC vigentes que no fueron modificados. En Navidad no se indican zonas de riesgos, pero en ciertas zonas con diversos usos de suelo se indica que la aprobación de proyectos está sujeta a estudios de riesgo, los que deberán contar con la aprobación de los organismos técnicos correspondientes. Esta nota al pie de la respectiva zona es usual encontrarla en PRC que no poseen especificidad normativa. Por su parte, en el PRC de Litueche se define "Zona R1 - Inundable", conformada por los terrenos que se constituyen en áreas de riesgo para los asentamientos humanos dadas sus condiciones hídricas, por inundación y franjas de protección de esteros y quebradas.

Otro caso es el de Pichilemu, en el cual luego del desastre, durante 2012, se aprueba una modificación al PRC que no tiene relación directa con zonificación o mitigación de riesgos. Las zonas de riesgos definidas por el PRC (2005) son zona R1, "Restricción por riesgo de inundación”, zona R2, "Restricción por riesgo de remoción (asociado a pendientes fuertes", y zona R3, "Restricción por riesgo de inundación con usos turísticos". Sin embargo, las modificaciones se realizan para generar proyectos de densificación, sólo para usos residenciales en las zonas A3 y A4.

Finalmente, el PRC de Machalí (1980) luego de la catástrofe, durante el año 2011, se replantea la vialidad estructurante y se modifican áreas habitacionales y de equipamiento. Entre 2011 y 2012 se realiza una serie de modificaciones que buscan precisar el cambio del PRC y luego, en 2013, se aprueba la modificación No 4 al PRC, la cual delimita áreas de riesgos geológicos y ajusta usos de suelo. Esta modificación se realiza en la zona de "riesgo natural asociado a pendientes", como "riesgo natural asociado a remoción en masa" y dentro de las zonas de restricción definen escalas de riesgos por inundación y remoción en masa.

En síntesis, en la región de O'Higgins los dos PRC modificados entre 2010 y 2014 (Pichilemu y Machalí) no se realizaron a través de la Ley de Sismos y Catástrofes, sino a través de un proceso regular y en la actualidad de las comunas que necesitaban modificaciones, dos de ellos no fueron modificados (Navidad y Litueche) (Figura 3).

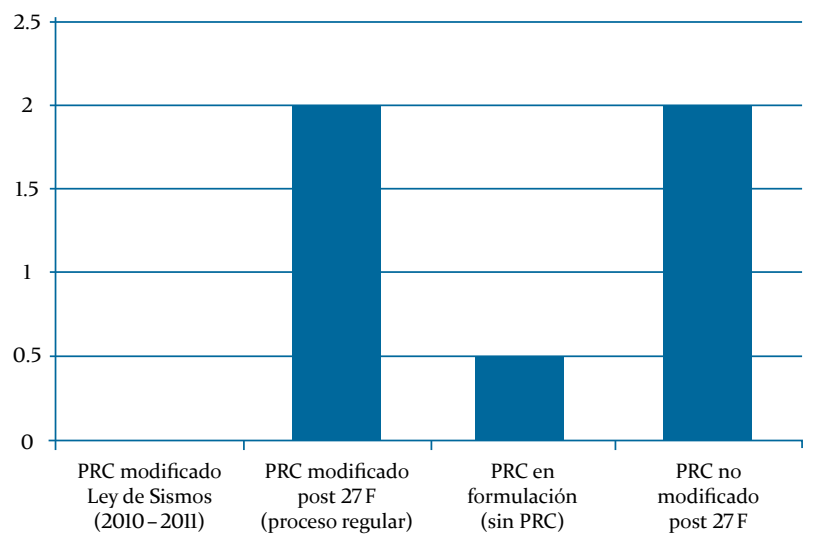

Figura 3: Grafico que muestra los PRC modificados post 27F en la región de O’Higgins (2010-2014) Fuente: CIGIDEN (2014) en base a información MINVU $(2010,2014)$.

\section{Caso de la Región del Maule}

La Región del Maule cuenta con 30 comunas $^{15}$, de las cuales 12 requirieron modificación o actualización de su PRC (MINVU, 2010) (Figura 4).

Hasta la fecha, las comunas de Licantén, Romeral, Hualañé, Pencahue, Maule, Empedrado y Chanco no poseen PRC, sólo poseen LU en las zonas donde se emplazan sus asentamientos más poblados.

En este contexto, cabe destacar como caso emblemático de la ausencia de IPT en esta región el caso de la comuna de Licantén, el cual definía sólo límite urbano en el Balneario de lloca (1938). Este balneario de la provincia de Curicó fue una de los más dañadas por el terremoto y por el posterior tsunami. Alrededor de un $70 \%$ de las construcciones, incluyendo las localidades conurbanas de Duao y La Pesca, quedaron destruidas tras la catástrofe (BBC, 2010).

Por otro lado, los PRC Vichuquén (1967) y Molina (1988) no fueron modificados en el período, siendo que en sus respectivos instrumentos son muy generales en cuanto zonificación y no definen
15. Cauquenes, Chanco, Pelluhue, Curicó, Hualañé, Licantén, Molina, Rauco, Romeral, Sagrada Familia, Teno, Vichuquén, Colbún, Linares, Longaví, Parral, Retiro, San Javier, Villa Alegre, Yerbas Buenas, Constitución, Curepto, Empedrado, Maule, Pelarco, Pencahue, Río Claro, San Clemente, San Rafael y Talca. 
zonas de riesgo. Por ejemplo, la zona de borde del lago Vichuquén sólo norma desde su potencial turístico y en el PRC de Molina, el borde del Canal Cerrillano se define como una zona de protección.

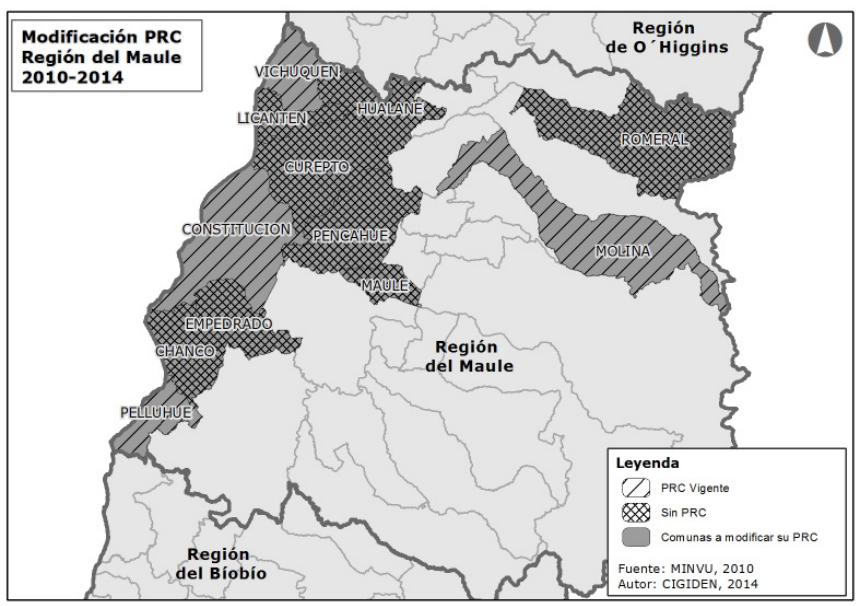

Figura 4: Mapa que muestra la cantidad de comunas que requirieron estudios de riesgo en la Región del Maule y cuáles de estos tienen PRC vigente y no lo tienen a la fecha. Fuente: CIGIDEN (2014) en base a información MINVU (2010, 2014).

El caso de Constitución es interesante de analizar cómo su modificación no tuvo relación con la catástrofe del 2010. Su PRC del año 1988 fue modificado luego de la catástrofe a través de una enmienda el año 2012, la cual indica que es posible incrementar la altura de edificación continua en la Zona ZI de 7 metros 8,4 metros. Es decir, no hubo modificación con respecto a zonas de riesgos, sino que se aprovechó la instancia para aumentar la altura de la edificación en un sector de la ciudad.

Finalmente, el caso de la comuna de Pelluhue es destacable en esta región, dado que en el año 2012 se aprueba un nuevo PRC como uno de los pocos casos exitosos del periodo. La modificación del PRC se ajustó rápidamente por contar con una Plan Regulador Intercomunal reciente. En su artículo 3.7 se definen "Áreas Restringidas al Desarrollo Urbano", en la cuales las áreas de riesgo normadas corresponden a "Áreas potencialmente inundables por anegamiento", "Áreas potencialmente inundables por desbordes de cauce", "Áreas potencialmente inundables por tsunami", "Áreas propensas a avalancha, rodados, aluviones" y "Áreas propensas a erosión acentuada".

En síntesis, en la región del Maule las modificaciones a los PRC entre 2010 y 2014 (Constitución y Pelluehue) no se realizaron a través de la Ley de Sismos y Catástrofes, sino a través de un proceso regular. Sin embargo, dos de las comunas que sí requerían actualizar su normativa no fueron modificadas (Vichuquén y Molina) y nueve se encuentran en formulación (Figura 5).

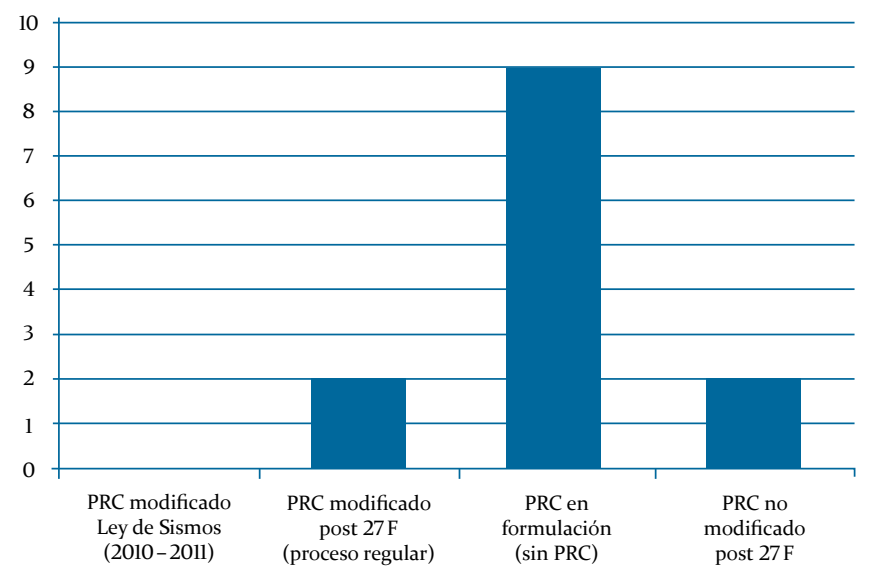




\section{Caso de la región de Bío-Bío}

La Región del Bío-Bío cuenta con 54 comunas $^{16}$, de las cuales 25 requirieron modificación o actualización de su PRC (MINVU, 2010) (Figura 6).

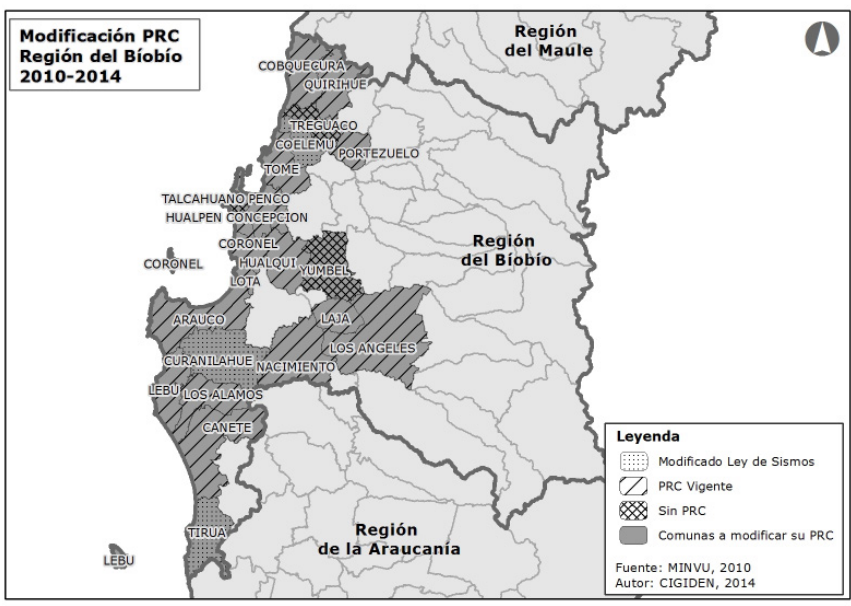

Figura 6. Mapa que muestra la cantidad de comunas que requirieron estudios de riesgo en la Región del Bío Bío y cuáles de estos tienen PRC vigente y no lo tienen a la fecha. Fuente: CIGIDEN (2014) en base a información MINVU (2010, 2014).

A diferencia de las regiones de Maule y O'Higgins, en esta región sí hubo modificaciones de PRC a través de la Ley de Sismos y Catástrofes, en las comunas de Curanilahue y Tirúa ${ }^{17}$. En estos tres casos, las modificaciones se realizaron en base al estudio de riesgos realizado por LEU en 2010. Entre las actualizaciones normativas, el PRC de Curanilahue (1982) no hacía referencia a zonas de riesgos, pero en su modificación de 2013 incluye nueva zona de riesgos por remoción en masa (avalancha) y el PRC de Tirúa se aprueba en 2012 incluyendo zonas de riesgos de tsunami, inundación fluvial y de remoción en masa (avalancha), los cuales se encuentran graficados como áreas de riesgo superpuestas a las distintas zonas del instrumento.

Además, en esta región existe una serie de comunas que tuvieron modificaciones en su PRC, pero no todas relacionadas a los estudios de riesgos realizados. Por ejemplo, la modificación del PRC de Portezuelo (2007), realizada durante 2012 amplía la zona habitacional mixta sin abordar la actualización de zonas de riesgo. El PRC de Tomé (2008) fue modificado luego de la catástrofe, en 2013, a través de una enmienda que no hizo referencia a las zonas de riegos definidas en el instrumento, incrementando densidad en un $20 \%$ la zona ZR3 (Zona habitacional 3) y ZRM3 (Zona Residencial Mixta 3)

EI PRC de Laja (2008) define zonas no edificables por riesgo de remoción en masa, por inundación, por protección de drenajes y de amortiguación ambiental, pero sus modificaciones en 2011 y 2013 no tienen que ver con aquellas zonas.

El PRC de Lebu (2009) indica zonas de restricción por inundación, remoción y protección de borde costero, "Playa de Mar", por interés y/o valor paisajístico y por riesgos de incendios forestales. Sin embargo, la modificación luego de la catástrofe en 2011 tiene relación con la delimitación de la Reserva Nacional de Isla Mocha.

El PRC de Los Ángeles (2007) contiene zonas inundables y potencialmente inundables, por cauces naturales, cauces artificiales y por afloramiento de napas subterráneas y estancamiento de aguas superficiales. Este instrumento fue modificado en 2011 para actualizar base cartográfica del plan, incorporando los desarrollos inmobiliarios realizados.

EI PRC de Arauco (1988) contiene zonas de protección ecológica fluvial (PEF), ecológica recreacional (PER), ecológica de dunas (PED), ecológica histórica (PEH) y ecológica de pendientes (PEP). Fue modificado luego de la catástrofe en 2010 y 2011, sin relación a las zonas de riesgos, sino asimilando cambios de usos.

Asimismo, el PRC de Talcahuano (2006) contempla una serie de zonas de riesgos clasificadas en áreas de edificación restringida, áreas no edificables y áreas de protección. Este instrumento ha tenido una serie de modificaciones, de las cuales tres se hicieron luego de la catástrofe. Las realizadas en 2010 y 2011, no tienen relación con las zonas de riesgos, pero sí la realizada en 2013,
6. Arauco, Cañete, Contulmo,

Curanilahue, Lebu, Los Álamos, Tirúa, Alto Bío-Bío, Antuco, Cabero, Laja, Los Ángeles, Mulchén, Nacimiento, Negrete, Quilaco, Quilleco, San Rosendo, Santa Bárbara, Tucapel, Yumbel, Chiguayante, Concepción, Coronel, Florida, Hualpén, Hualqui, Lota, Penco, San Pedro de la Paz, Santa Juana, Talcahuano, Tomé, Bulnes, Chillán, Chillán Viejo,

Cobquecura, Coelemu, Coihueco, E Carmen, Ninhue, Ñiquén, Pemuco, Pinto, Portezuelo, Quillón, Quirihue, Ránquil, San Carlos, San Fabián, San Ignacio, San Nicolás, Treguaco y Yungay.

17. Información entregada con fecha 30/09/2014 por Angela Soriano, Geógrafa de la División de Desarrollo Urbano (DDU), Ministerio de Vivienda y Urbanismo (MINVU). 
la cual indica modificación al sustituir parte de la zona ZPCe "Zona de protección de Cerro" por una nueva zona definida "Zona residencial ZH-8T" en el sector Península Tumbes. Este sector tenía una condición "no edificable" con el objeto de asegurar el ecosistema de la zona y de prevenir y controlar su deterioro.

Por otro lado, existen dos comunas que sólo contaban con límite urbano y que luego de la catástrofe publicaron su PRC. Tal es el caso del PRC de San Pedro de La Paz, que fue publicado en 2011 y en el cual se definen una serie de zonas de riesgos. La zona de riesgo de borde costero (ZRC) se clasifica en sub fajas, en las que se indican condiciones de edificación y estructura vial. Además, se encuentran las zonas riesgo de remoción en masa (ZRR) y de riesgo de inundación (ZRI-1 y ZRI-2). Por otra parte, en la normativa se indica que estas zonas deben dar cumplimiento al anexo "Estudio de riesgos" y se indica que para aprobar cada proyecto de loteo, urbanización o edificación se debe hacer un estudio revisado por un profesional especialista.

EI PRC de Coronel se publica luego de la catástrofe, durante 2013, y en su normativa se definen áreas potencialmente inundables por anegamiento, por susceptibilidad de tsunami y propensión a avalanchas, rodados y aluviones. En esta clasificación definen zonas restringidas, por riesgos generados por la intervención humana ( $\mathrm{ZRIH}-1, \mathrm{ZRIH}-2, \mathrm{ZRIH}-3)$, inundación por desborde de cauces (ZRI) y de protección de recursos de valor natural en borde costero (ZP-1 y ZP-2).

En 2010 las comunas Treguaco (1998), Yumbel (2009) y Hualpén (1990) no contaban con PRC, sino que solo Límite Urbano (LU). Posteriormente sus instrumentos no fueron actualizados.

En síntesis, en la región del Bío-Bío, existen tres PRC modificados a través de la Ley de Sismos y Catástrofes, además de otros siete que se modificaron a través de proceso regular. En la actualidad, entre las comunas que necesitaban modificaciones a sus PRC, dos se encuentran aún en formulación, dos fueron publicados y once aún no han sido modificados (Figura 7).

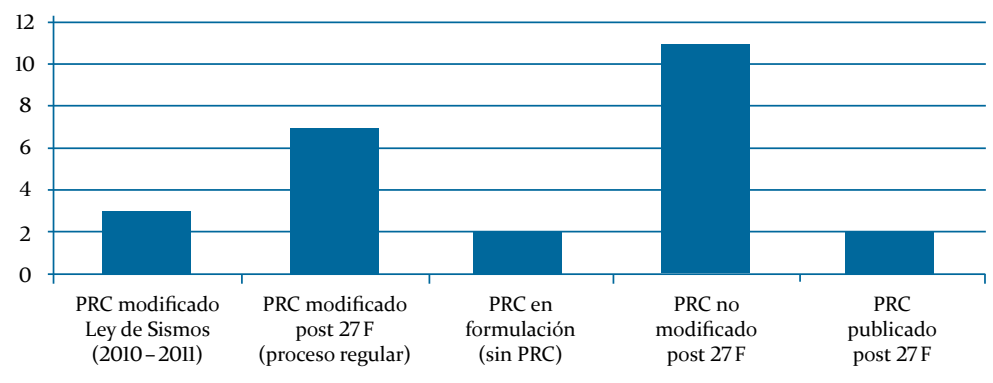

Figura 7. Gráfico que muestra los PRC modificados post 27F en la región del Bío Bío (2010-2014) Fuente: CIGIDEN (2014) en base a información MINVU $(2010,2014)$.

\section{CONCLUSIONES}

\section{Ambigüedad en la consideración del riesgo en los IPT}

A partir del análisis de las modificaciones realizadas a los PRC de las comunas más afectadas de las regiones de Maule, O'Higgins y Bío-Bío, se puede concluir que, en primer lugar, no ha existido una definición clara de cómo los estudios de riesgo son incorporados en los IPT. Por una parte, en la OGUC se indica que es un "documento técnico elaborado por uno o más profesionales especialistas, cuyo objetivo es definir peligros reales o potenciales para el emplazamiento de asentamientos humanos" (MINVU, 2004), no indicando qué metodología se deben ocupar los profesionales a cargo para cada tipo de riesgo analizado.

Por otro lado, en el artículo 2.1.17 de la OGUC se indica que en los IPT "podrán definirse áreas de riesgo, cuando proceda y previo estudio específico, por constituir un peligro potencial para los asentamientos humanos" (MINVU, 2012). Luego, cuando se reconoce el riesgo una zona, se requiere un "estudio fundado" previo a aplicar las normas urbanísticas definidas. Para este estudio no se define una metodología, ni se especifica un estándar mínimo de mitigaciones a realizar. De esta forma, todas las sugerencias entregadas en los estudios realizados pueden no ser consideradas en el IPT, dado que sólo se exige contar con el estudio y no necesariamente integrarlo en la normativa.

La OGUC en su artículo 2.1.5. indica que en los PRI y PRC se establecerán, "previo estudio fundado de riesgos elaborado por profesionales especialistas, zonas no edificables o de edificación restringida, por constituir un peligro potencial para los asentamientos humanos". Además, 
se indica en el artículo 2.1.17. que en los casos en que la restricción para edificar se deba a razones de seguridad ante desastres naturales $u$ otros motivos subsanables mediante la incorporación de obras de ingeniería u otras suficientes, un proyecto determinado podrá ser autorizado de acuerdo a "estudios fundados, elaborados por un profesional especialista". Por otro lado, la OGUC, indica que mediante "estudios de mayor detalle, los PRC podrán precisar o disminuir las áreas afectas a riesgo o de protección ambiental", pero, sin indicar específicamente los procedimientos técnicos de este detalle.

Asimismo, en el contexto normativo actual, sólo los PRC y PRI o PRM tienen las facultades para definir áreas de riesgo, no así los IPT de los LU o los Planes Seccionales. En los casos estudiados de las regiones afectadas por la catástrofe del $27 \mathrm{~F}$, se puede identificar que existen comunas que fueron muy afectadas y que sólo contaban con la definición de un LU.

Comprendiendo el contexto de modificaciones que necesariamente requieren las normativas sobre áreas de riesgos en Chile, cabe destacar que se han retirado de tramitación tales como el Decreto $N^{\circ} 25 / 2013$ que reglamentaba la Ley Nº 20.582 sobre reconstrucción que modificaba cuatro leyes: la LGUC, la Ley de Sismos y Catástrofes, el DL No1.305 ${ }^{18}$ y la Ley $N^{0} 20.251^{19}$

Desde 2015 el MINVU está tramitando una modificación sustantiva del artículo 2.1.17 de la OGUC que aborda gran parte de las temáticas recién indicadas. Estas modificaciones están en sintonía con los planteamientos de la mesa de trabajo de Planificación y Riesgos iniciada en 2014 por el Centro de Investigación para la Gestión Integrada de Riesgo de Desastres (CIGIDEN). Uno de los temas más relevantes no abordados en esta modificación dice relación con el procedimiento de validación del "estudio de riesgo" en el proceso de tramitación del IPT. Para la mesa, el proceso de estudio de riesgos debería realizarse con un acto administrativo distinto del IPT. Esto se debe a que en modelo actual los estudios de riesgo son presentados como insumo en el Concejo Municipal, siendo posible cuestionar los resultados por parte de los concejales y alcalde.

\section{Inconsistencias entre la Ley de Sismos y Catástrofes y los procesos de modificación de IPT}

La planificación de riesgos es una materia que tiene menos de 20 años en Chile y desde entonces se ha estado desarrollando. Por ejemplo, desde los IPT disponibles se han separado en las definiciones normativas como los conceptos de "zonas no edificables", "áreas de riesgo" y "áreas de protección" (MINVU, 2012). Sin embargo, a pesar de este avance, la catástrofe del 27F mostró las falencias que posee la institucionalidad, en cuanto a los instrumentos disponibles para la gestión de riesgos y reconstrucción.

La evidencia demuestra que la implementación de la Ley de Sismos y Catástrofes tuvo un bajo impacto en la posibilidad de actualizar los IPT de las zonas afectadas en el plazo de 2 años. Se pudo ver que el modelo de fast track de años requiere de mayor especificidad para su aplicación exitosa y para evitar un gasto público sin sentido, al no poder aprobarse en el período.

Mediante el análisis de las modificaciones realizadas en los PRC de las regiones afectadas por la catástrofe del 27F, se pudo corroborar que de las 234 comunas que requerían modificaciones o actualización de los PRC en base a estudios de riesgo, sólo 11 de ellas (5\%) se realizaron a través y de acuerdo a la Ley de Sismos y Catástrofes (Figura 8).
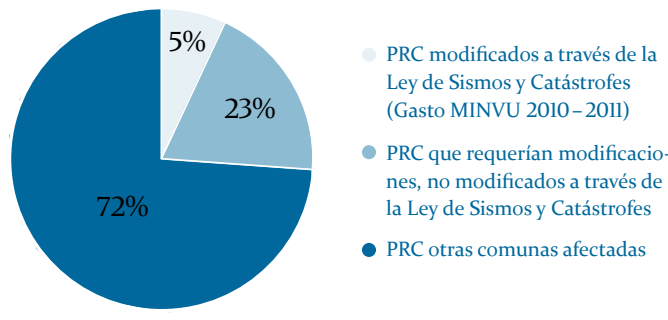

Por otro lado, el análisis manifiesta que del total PRC modificados post 27F (2010-2014), tanto en la Región del Maule, O’Higgins, como en la del Bío-Bío, sólo tres instrumentos fueron modificados a través de la Ley de Sismos y Catástrofes (5\%), nueve fueron modificadas a través de proceso regular $(21 \%)$, siendo muchas de ellas sin relación al estudio de riesgo realizado. Además, 16 comunas (35\%) que requerían modificación no han sido actualizadas aún y 12 de estas comunas aún no tienen PRC, sólo LU (12\%) (Figura 9).
Figura 8. Gráfico que muestra el total nacional de PRC modificados a través de la Ley de Sismos y Catástrofes (Gasto MINVU 2010-2011). Fuente: CIGIDEN (2014) en base a información MINVU (2010, 2014)

18. Decreto Ley 1305 (1975). "Reestructura y regionaliza el ministerio de la vivienda y urbanismo [en línea]. Biblioteca del Congreso Nacional de Chile. Disponible en: http://www.leychile.cl/ navegar?idnorma $=6564$

19. Ley 20251 (2008). “Establece un procedimiento simplificado para los permisos de edificación de viviendas sociales". [en línea]. Biblioteca del Congreso Nacional de Chile. Disponible en: http://www.leychile.cl/ navegar?idley $=20251$ 

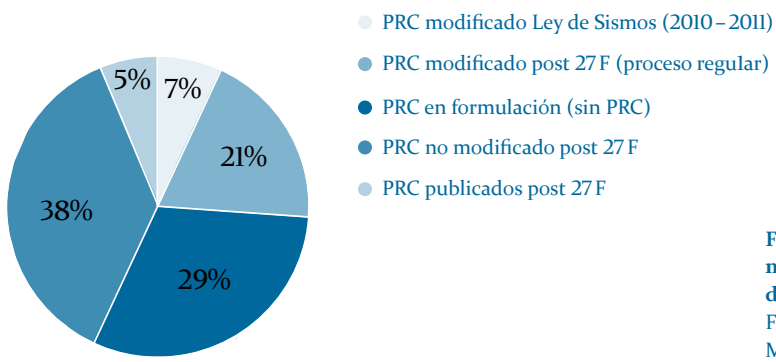

Figura 9. Gráfico que muestra el total de PRC modificados entre 2010 y 2014 en las regiones del Maule, O'Higgins y Bío-Bío

Fuente: CIGIDEN (2014) en base a información MINVU $(2010,2014)$

Por otro lado, es necesario destacar que no todas las modificaciones de los PRC realizadas entre 2010 y 2014 tuvieron relación con la catástrofe (Figura 9), como es el caso de la modificación del PRC de Constitución, la cual no define una nueva normativa en cuanto a zona de riesgos y proyectos de mitigación, sino su propuesta está orientada a generar mayor rentabilidad inmobiliaria en zonas que fueron afectadas por el terremoto.

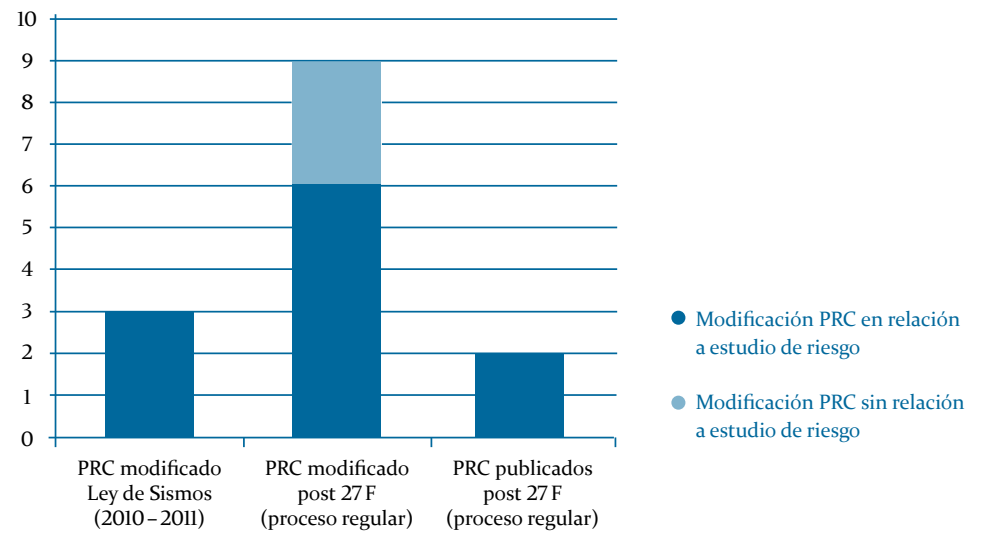

Figura 10. Gráfico que muestra el total de PRC modificados entre 2010 y 2014 en las regiones del Maule, O’Higgins y Bío.Bío. Fuente: CIGIDEN (2014) en base a información MINVU (2010, 2014).

Asimismo, desde el análisis se evidencia que existen localidades que fueron fuertemente afectadas por la catástrofe y que, hasta el día de hoy, sólo cuentan con la definición de LU, por lo que son aún totalmente vulnerables a futuros eventos. Por otro lado, además de los frágiles instrumentos existentes, éstos sólo regulan ciertas zonas urbanas, lo cual fue crítico para la situación post-catástrofe del $27 \mathrm{~F}$, dado que comparativamente los sectores rurales fueron más afectados que las áreas urbanas.

Cuando se observa la población total afectada del 27F, siempre las cifras de lo rural serán proporcionalmente menores, y de allí la tendencia a desestimar este grupo de población para efectos de la emergencia y posterior reconstrucción, más aún si las políticas públicas en torno a este sector son difíciles de identificar. La evidencia es que hasta la fecha no existen datos oficiales de población rural afectada, ni registros de daños o pérdidas asociadas a ella.

\section{Ausencia de participación ciudadana en el proceso de actualización de los IPT}

Es llamativo considerar que los procesos de diseño de los planes de reconstrucción financiados con recursos privados mostraron diversas aproximaciones a la participación ciudadana. Se pudo verificar el esfuerzo por involucrar a las comunidades en las definiciones sustanciales y carteras de proyecto de los planes. Si bien todo se realizó sin un marco legal de referencia, las actividades de participación fueron consideradas clave para la validación de los planes. Sin embargo, el sistema fast track de 2 años de la Ley de Sismos y Catástrofes permite actualizar los IPT sin participación ciudadana. Esto ha sido entendido como un incentivo, pero al mismo tiempo esconde una falta de compresión del rol que la cabe a la comunidad en la planificación territorial.

En este contexto, es importante cuestionar el rol de los planificadores y de las instituciones a cargo de la planificación territorial, dado que, desde su posición, deberían iniciar el diálogo público pre y post desastre. Se torna necesario tener una mirada a largo plazo, aprender de lo ocurrido y transmitirlo a las comunidades vulnerables a riesgos, y especialmente las comunidades ya 
afectadas por catástrofes, las dimensiones del problema a través de una difusión pública eficaz. Esto implica la participación de una mayor cantidad de actores clave, promoviendo lograr un consenso sobre principios generales y elementos de acción desde las normativas vigentes. Lo primordial es establecer equipos de planificación con participación ciudadana, con el fin de generar apoyo público informado para generar planes de mitigación de riesgos desde lo local (Schwab, 2010).

Una de las causas más claras del fracaso de la planificación ante riesgos en Chile, es que los planificadores no han sido parte del proceso de los estudios de riesgos locales, lo cual ha dificultado la definición de planes de mitigación para la reducción de la probabilidad de catástrofes. Por esta razón, es necesario que los actores locales estén involucrados en el proceso, en la discusión de alternativas de mitigación de riesgos, la política de uso del suelo y la planificación, teniendo en cuenta la vulnerabilidad específica de cada comunidad. Las debilidades estructurales del proceso local de planificación para la mitigación de riesgos surgen desde ese error inicial.

Por otro lado, a pesar de las falencias que presenta la actual institucionalidad en cuanto a planificación de riesgos, existen oportunidades de avance. Cabe destacar, la modificación al artículo 2.1.17 OGUC que regula las áreas de riesgo, en proceso y la implementación de la nueva propuesta de Política Nacional de Desarrollo Urbano (PNDU) publicada en 2013. En esta última se declara que, entre los aspectos no resueltos en la evolución de las ciudades chilenas, se encuentra "la falta de herramientas para gestionar los riesgos naturales" (PNDU, 2013). A partir de este diagnóstico se propone como uno de los objetivos "Objetivo 3.2. Identificar y considerar los riesgos naturales y antrópicos".

- Fomentar la investigación y estudio sobre los riesgos naturales y antrópicos asociados al uso del territorio para asentamientos humanos, incorporando dicha información a los Instrumentos de Planificación Territorial.

- Integrar el concepto de reducción de riesgo de desastres en los Instrumentos de Planificación Territorial de las diferentes escalas.

- Complementar las disposiciones sobre riesgos naturales incorporadas en los Instrumentos de Planificación Territorial con planes de monitoreo, de gestión de emergencias, de información y capacitación ciudadana. Asegurar que se construyan y señalen adecuadamente las vías de evacuación y las áreas de seguridad.

- Establecer reglas preestablecidas para el emplazamiento de construcciones en áreas de riesgo, bajo requisitos de estudios específicos, de medidas de prevención o la ejecución de obras de resguardo o mitigación.

- Fomentar en todas las escalas la gestión y prevención de riesgos por pasivos ambientales.

A través de estos objetivos definidos hacia el largo plazo desde la PNDU, queda de manifiesto que "los desastres no se construyen en un día" (Freudenburg et al. 2009). Sino que son producto de numerosas decisiones de planificación durante muchos años, donde la mitigación es un trabajo constante que requiere diligencia y paciencia política. La aplicación de medidas es, a menudo, un desordenado proceso, por lo que es necesario desarrollar herramientas para minimizar la vulnerabilidad en el tiempo. En este sentido, los avances se deben desarrollar a diversas escalas, desde los amplios lineamientos de una política nacional, hasta la modificación de la normativa de un área de riesgos específica; e integrando a diversos actores, incluyendo el rol las máximas autoridades nacionales, hasta la participación del habitante asentado en un área de riesgo.

\section{Hacia una Agenda de Perfeccionamiento de la Planificación Territorial}

Todo lo anterior deja en evidencia la necesidad de avanzar en el perfeccionamiento del sistema de planificación territorial. A continuación, se presentan algunos de los principales desafíos que podrían constituir esta agenda:

\section{a.Respecto a los Instrumentos de Planificación Territorial}

1. Definiciones conceptuales respecto a riesgo:

- Clarificación de riesgos, peligros, amenazas y vulnerabilidad, áreas y zonas.

- Coherencia en instrumentos legales (LGUC, OGUC 2.1.17, 5.1.15, Circulares DDU).

- Incorporación de todos los riesgos y amenazas.

2. Perfeccionamiento de consideración de riesgo en IPT:

- Caracterización de amenazas, vulnerabilidad y riesgo.

- Perfeccionamiento de mapas de riesgo en los Planes Reguladores Intercomunales, promoción de estudios de riesgo según unidades territoriales / geográficas, no solo político administrativas 
- Perfeccionamiento de relación de normas urbanísticas y toma de decisiones como es el caso de las zonas de exclusión del desarrollo urbano.

3. Perfeccionamiento y formalización de estudios fundados de riesgo:

- Definición de metodologías oficiales, evaluando la estandarización de metodologías posibles de utilizar.

- Revisión de los procedimientos de ejecución de los IPT respecto a los estudios de riesgo. Evaluando la posibilidad de separar los estudios de riesgo del proceso IPT, que sean aprobados de forma independiente y que sean aportados como insumo técnico a los IPT.

- Formalización de tipos de productos relacionados dentro de los estudios de riesgo.

4. Procedimientos de actualización post-desastre

- Condiciones de actualización de los IPT en Ley de Sismos y Catástrofes (art. 27, Ley $N^{016.282)}$ asegurando que se cumplan los objetivos relacionados a la zonificación de riesgos en plazos acotados.

5. Sistemas de información pública

- Perfeccionamiento de los instrumentos y procesos que permitan que la población acceda a la información clave relacionada a las zonas de riesgo y los planes de evacuación.

6. Orientaciones respecto a relocalizaciones y expropiaciones

- Avanzar en la definición de instrumentos que permitan asegurar los procesos de relo calización de viviendas e infraestructura crítica emplazados en zonas de riesgo.

\section{b. Respecto a los Instrumentos de Gestión}

7. Formalización e institucionalización de Planes de Reconstrucción

- Formalización de planes como instrumentos oficiales y vinculantes a las decisiones de regulación, inversión y gestión.

- Avanzar en la formalización de modelos de gestión u hojas de ruta para la reconstrucción que impliquen organigramas institucionales y financiamiento.

- Formalizar los sistemas de seguimiento y cumplimiento de metas de los procesos.

8. Planes de evacuación y recuperación

- Desarrollar un sistema de evacuación basado en planes y no solo en mapas, que estén relacionados con los IPT.

- Formalizar y habilitar las zonas de seguridad y puntos de encuentro.

- Perfeccionar el sistema de albergues y barrios de emergencia asegurando la calidad de la habitabilidad transitoria.

9. Obras de mitigación

- Definición de nuevos estándares según los tipos de obras y el nivel de tolerancia al riesgo que determine el país.

- Perfeccionamiento de riesgos en Sistema Nacional de Inversiones.

\section{AGRADECIMIENTOS}

Proyectos FONDAP N¹5110017 de la Comisión Nacional de Investigación Científica y Tecnológica de Chile. Centro de Investigación para la Gestión Integrada de Riesgos de Desastres Naturales. A Laura Guanco y Rosario Walker por el apoyo en trabajo de investigación.

\section{REFERENCIAS}

Bahadur, A. \& Tanner, T. (2014). Transformational resilience thinking: putting people, power and politics at the heart of urban climate resilience. Environment \& Urbanization, 26(1), 1-15. DOI: $10.1177 / 0956247814522154$

BBC. (2010, 2 Mar 2010). Chilenos claman por ayuda tras el terremoto. BBC Mundo. Recuperado el 29 de Abril 2017 del sitio web BBC: http://www.bbc.com/mundo/america_latina/2010/03/100302_2144_ chile_maremoto_ayuda_jaw.shtml

Bello, O., Ortiz L. \& Samaniego J. (2013). La estimación de impacto económico y social de los desastres naturales en América Latina, 1972-2010. Santiago de Chile: CEPAL. 
CEPAL. (2014). Manual para la evaluación de desastres. Unidad de Evaluación de Desastres de la División de Desarrollo Sostenible y Asentamientos Humanos. Santiago de Chile: CEPAL.

DDU. (2014). Propuesta Elaborada por la División de Desarrollo Urbano. Versión 9 de octubre 2014. Documento de trabajo sobre áreas de riesgo, comparado reconstrucción en consulta. Santiago de Chile: División de Desarrollo Urbano, Ministerio de Vivienda y Urbanismo (MINVU).

EPA. (200o). Environmental planning for communities: a guide to the environmental visioning process utilizing a geographic information system (GIS). Cincinnati, Ohio: United States Environmental Protection Agency, Office of Research and Development \& DIANE Publishing.

Ferrada-Nehme \& IEUT. (2011). Análisis de la institucionalidad, la regulación y los sistemas de gestión y ordenamiento del territorio en Chile. Informe final para Ministerio de Energía. Santiago de Chile: Gobierno de Chile.

Gobierno de Chile. (2014). Diagnóstico Estado de la Reconstrucción, Terremoto y tsunami del 27 de febrero de 2010. Delegación Presidencial para la Reconstrucción, Ministerio del Interior y de Seguridad Publica, 4 de junio de 2014. Santiago de Chile: Gobierno de Chile.

LEU. (2010). Estudio de riesgo de sismos y maremoto para comunas costeras de la región del Bio-Bío. Concepción: Laboratorio de Estudios Urbanos, Universidad del Bío-Bío.

MINVU. (2013). Reconstrucción urbana post 27F. Instrumentos de Gestión y Planificación Territorial. Santiago de Chile: Dirección de Reconstrucción, MINVU.

MINVU. (2012). Manejo de las Áreas de Riesgo en los Instrumentos de Planificación Territorial. Mayo de 2012. Concepción: División de Desarrollo Urbano.

MINVU. (2012). Tratamiento de los Riesgos en los Instrumentos de Planificación Territorial. Julio de 2012. Puerto Montt: MINVU.

MINVU. (2010). Procedimiento para Actualizar Planes Reguladores. Santiago de Chile: MINVU.

MINVU. (2009). Planificación urbana, formulación y contenidos Plan Regulador Comunal. Circular Ord. Nº935 DD27. Diciembre 2009. Santiago de Chile: MINVU.

MINVU. (2004). Resumen de modificaciones y rectificaciones de la Ordenanza General de Urbanismo y Construcciones. Abril de 2014. Santiago de Chile: MINVU.

Moris, R. (2014). Notas respecto a los aprendizajes del proceso de reconstrucción en Chile después del 27 de febrero de 2010. Informe CIGIDEN, Mayo de 2014. Santiago de Chile: CIGIDEN.

Moris, R., R. Cienfuegos, F. Arenas F., J. Giron.s, C. Escauriaza, C. Ledezma, M. Lagos, R. Hidalgo, P. Osses, L. Moya \& J. Heitmann. (2010). Estudio de riesgo de sismos y maremoto para comunas costeras de las regiones de O'Higgins y del Maule. Santiago de Chile: Observatorio de Ciudades, Pontificia Universidad Católica de Chile.

OECD. (2012). Global Modelling of Natural Hazard Risks, Enhancing Existing Capabilities to Address New Challenges. September 2012. Paris: Organization for Economic Co-operation and Development (OECD), Global Science Forum. Recuperado el 29 de Abril 2017 del sitio web OECD: https://www.oecd.org/science/Final\%2oGRMI\%2oreport.pdf

PNDU. (2013). Política Nacional de Desarrollo Urbano. Ciudades Sustentables y Calidad de Vida. Versión Final 03.05.2013. Santiago de Chile: MINVU.

Ruiz, S. \& Madariaga, R. (2012). Sismogénesis, proceso de ruptura y réplicas del mega terremoto del Maule 2010. En Moroni, M. O. (Ed.), Mw = 8.8 : Terremoto en Chile, 27 de febrero de 2010 (pp. 13-30). Santiago de Chile: Universidad de Chile.

Schwab, J. (2010). Hazard mitigation: integration best practices into planning. Planning Advisory Service. Report Number 506. Chiago: American Planning Association.

Swanstrom, T. (2008). Regional Resilience: A Critical Examination of the Ecological Framework. Working Paper 2008-07. Baltimore, MD: Institute of Urban and Regional Development (IURD).

UNISDR. (2005). Marco de Acción de Hyogo para 2005-2015: Aumento de la resiliencia de las naciones y las comunidades ante los desastres. Kobe: UNISDR. 